\title{
ELECTROCHEMICAL OXIDATION OF IODIDE AT A GLASSY CARBON ELECTRODE IN METHYLENE CHLORIDE AT VARIOUS TEMPERATURES
}

\author{
I.S. EL-HALLAG \\ Chemistry Department, Faculty of Science, Tanta University, Tanta 31527, Egypt \\ (Received: April 13, 2009 - Accepted: September 24, 2009)
}

\begin{abstract}
Anodic electrooxidation of iodide in $0.1 \mathrm{~mol} \mathrm{~L}^{-1} \mathrm{TBAP} / \mathrm{CH}_{2} \mathrm{Cl}_{2}$ was studied electrochemically via cyclic voltammetry, convolution transforms voltammetry, chronoamperometry and chronopotentiometry techniques at a glassy carbon electrode (GCE) at various temperatures ranging from $-20{ }^{\circ} \mathrm{C}$ to 21 ${ }^{\circ} \mathrm{C}$. It was found that at less positive potential triiodide $\left(\mathrm{I}_{3}^{-}\right)$is formed followed by a moderate fast chemical process, while at more positive potential, the triiodide is oxidized to iodine $\left(\mathrm{I}_{2}\right)$ followed by another chemical process, i.e $E C_{1} E C_{2}$, scheme. The effect of lowering the temperature on the heterogeneous electron transfer rate constant and the diffusion coefficient was discussed. The relevant chemical and electrochemical parameters of the electrode reaction were determined. The accurate test of the parameters evaluated experimentally was verified by comparing the experimental voltammograms with the simulated one.
\end{abstract}

Keywords: Convolution transforms voltammetry, electrochemical parameters, digital simulation, chronoamperometry, chronopotentiometry.

\section{INTRODUCTION}

Iodide can function as an antioxidant as it as reducing species that can detoxify reactive oxygen species such as hydrogen peroxide. ${ }^{1-7}$ Iodine is an essential trace element, playing an important role in mental development, growth, and basic metabolisms. ${ }^{8,9}$

Iodide can be used to treat patients with hyperthyroidism due to its ability to block the release of thyroid hormone (TH), known as the Wolff-Chaikoff effect, from the thyroid gland. ${ }^{10}$ At the same time, iodine species belong to the toxic elements, especially because of one of its radioactive isotopes, 129 $\mathrm{I}$, which is weakly absorbed on minerals ${ }^{11}$ and has a long half-life $\left(1.7 \cdot 10^{7}\right.$ years), making it able to reach the biosphere before decaying to significant level.

Iodide-containing ionic liquids ${ }^{12}$ based on imidazolium cations ${ }^{13,14}$ have been extensively considered as non -volatile substitutes for liquid iodide electrolytes in dye-sensitized photo electrochemical (DSPEC) cells. ${ }^{15}$ The performance of DSPEC cells employing ionic liquid electrolytes is greatly influenced by the composition of the ionic liquid mixtures, their structure and properties. It was found ${ }^{16}$ that addition of iodine and consequent formation of an $\mathrm{I}^{-}\left(\mathrm{I}_{3}^{-}\right.$redox couple and $/$or possible polyiodide species (depending upon the iodine concentration) favourable affects ionic conductivity. ${ }^{4,17}$

Alkyl quaternary ammonium halides (AQAH) was used as corrosion inhibition of iron in acidic solution. ${ }^{18}$ The results show that besides the concentration, the structure of alkyl groups and the type of halide ions of these AQAH inhibitors greatly influence the inhibition efficiency.

Up till now, nothing concerning the electro-oxidation behaviour of iodide in $\mathrm{CH}_{2} \mathrm{Cl}_{2}$ via convolutive voltammetry. Tetrabutylammonium iodide (Figure 1) was used as a source of iodide has been reported in literature.

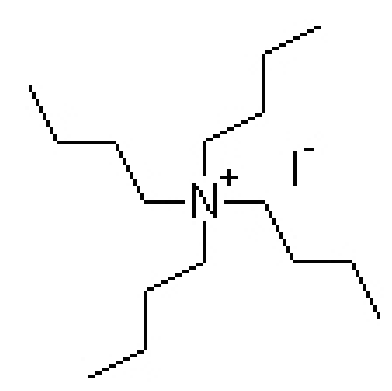

Figure 1
The aim of this study is, firstly, to investigate the electrochemical behaviour of iodide in $0.1 \mathrm{~mol} \mathrm{~L}{ }^{-1} \mathrm{TBAP} / \mathrm{CH}_{2} \mathrm{Cl}_{2}$ in more detailed via cyclic voltammetry, convolution transforms voltammetry, chronoamperometry, chronopotentiometry and digital simulation techniques; secondly, to investigate the effect of lowering the temperature on the values of heterogeneous rate constant $\left(\mathrm{k}_{\mathrm{s}}\right)$ and diffusion coefficient (D) and thirdly to propose the electrode reaction pathway of iodide in accord with the experimental results, as well as verification of the experimental chemical and electrochemical parameters via digital simulation.

\section{Experimental Section}

\section{Materials and solutions}

Tetrabutylammonium iodide (TBAI) as a source of iodide, tetrabutylammonim perchlorate (TBAP) and methylene chloride $\left(\mathrm{CH}_{2} \mathrm{Cl}_{2}\right)$ were analytical grade and used as supplied. Stock solution of $2 \times 10^{-3} \mathrm{~mol} \mathrm{~L}^{2}$ of TBAI under investigation was prepared in $0.1 \mathrm{~mol} \mathrm{~L}-1$ TBAP/ $/ \mathrm{CH}_{2} \mathrm{Cl}_{2}$.

\section{Apparatus}

Cyclic voltammetry, Convolution voltammetry, chronoamperometry, and chronopotentiometry experiments were performed using a Princeton Applied Research (PAR) Computer-controlled Potentiostat Model 363 (PAR, Oak Ridge, TN, USA). A micro-electrolysis cell with a three electrode system including a glassy carbon electrode (GCE) as the working electrode's area, a platinum sheet auxiliary electrode and a silver wire in contact with saturated lithium chloride in $\mathrm{CH}_{2} \mathrm{Cl}_{2}$ / TBAP as a reference electrode was used (Fluka $\mathrm{AG})$. Convolution - deconvolution voltammetry was carried out on PC computer using EG \& G Condecon software package. Digital simulation of the data for cyclic voltammetric experiments was performed on PC computer using EG \& G Condesim software package. The machine was programmed in Pascal. The simulation procedure was carried out using finite differences techniques. ${ }^{19-21}$ Algorithms for the simulation program were coded and implemented into the Condesim software package supplied by EG \& G .All the measurements were automated and controlled through the programming capacity of the apparatus.

\section{Procedure}

A $2 \times 10^{-3} \mathrm{~mol} \mathrm{~L}^{-1}$ solution of TBAI was introduced into the electrolysis cell containing $10 \mathrm{ml}$ of $0.1 \mathrm{~mol} \mathrm{~L}^{-1}$ tetrabutyl ammonium perchlorate (TBAP) dissolved in methylene chloride and then degassed thoroughly with oxygen - free nitrogen, while an atmosphere of nitrogen was maintained over surface of the solution during the measurements. The electrochemical measurements were carried out using cyclic voltammetry, convolutive volummetry, chronoamperometry and chronopotentiometry techniques. The measurements were carried out at temperature ranging from $21{ }^{\circ} \mathrm{C}$ to $-20^{\circ} \mathrm{C}$. 


\section{RESULTS AND DISCUSSION}

\section{Cyclic voltammetry of iodide in TBAP}

Cyclic voltammogram of $2 \times 10^{-4} \mathrm{~mol} \mathrm{~L}^{-1}$ solution of iodide recorded in $0.1 \mathrm{~mol} \mathrm{~L}^{-1} \mathrm{TBAP} / \mathrm{CH}_{2} \mathrm{Cl}_{2}$ at a glassy carbon electrode and scan rate of $0.2 \mathrm{~V}$ $\mathrm{s}^{-1}$ exhibited two anodic oxidative peaks $\left(E_{p a l}(I)=0.510 \mathrm{~V}\right)$ and $E_{p a 2}(I I I)=$ $0.941 \mathrm{~V}$ coupled with an cathodic peaks $E_{p c l}(\mathrm{III})=0.385 \mathrm{~V}$ and $E_{p c 2}(\mathrm{IV})^{2}=0.65$ $\mathrm{V}$ at $21{ }^{\circ} \mathrm{C}$ (Fig.2A). The two coupled peaks indicate the presence of a two chemical processes following the two steps of the quasi-reversible electron transfer $\left(E C_{1} E C_{2}\right.$ mechanism) ${ }^{22}$ The first chemical process $\left(C_{l}\right)$ result from combination between iodine and iodide to give triiodide $\mathrm{I}_{3}^{-}$while the second chemical process $\left(C_{2}\right)$ arising from the slow interaction between the generated iodine $\mathrm{I}_{2}$ and the solvent. This interaction due to the dielectric constant of methylene chloride is below 15 , substantial ion association begins to take place. $\mathrm{CH}_{2} \mathrm{Cl}_{2}$ as a donor solvent promote the ionization of covalent compounds to form intimate ion - pairs. The dissociating power of a $\mathrm{CH}_{2} \mathrm{Cl}_{2}$ solvent, which is its ability to promate dissociation of an ionic solute or a contact ion-pair, is largely a function of the dielectric constant.. Ionization is promoted in a donor solvent by solvation of cations. For example iodine $I_{2}$ is ionized in a donor solvent, $\mathrm{d}$, according to the reaction: ${ }^{23}$

$$
2 \mathrm{I}_{2}+2 \mathrm{~d} \quad 2 \mathrm{dI}_{2} \quad\left[\mathrm{I} \mathrm{d}_{2}^{+}\right]\left[\mathrm{I}_{3}^{-}\right]
$$

In the selected range of scan rates $\left(0.05-2 \mathrm{~V} \mathrm{~s}^{-1}\right)$, the difference in the peak potentials $(\Delta E=E-E)$ of the first anodic peak are varies between 59 $-94 \pm 3 \mathrm{mV}$ which more than the expected value $(29 \mathrm{mV})$ for two - electron Nernstian' process. ${ }^{24}$

This may be attributed to the quasi-reversibility rate of electron transfer in addition to some uncompensated solution resistance of the $\mathrm{CH}_{2} \mathrm{Cl}_{2}$ solution. ${ }^{25}$ Fig.2B indicates an example response of the cyclic voltammogram of iodide at sweep rate of $0.1 \mathrm{~V} / \mathrm{s}$, demonstrating the absence of the coupled reductive peaks in the backward direction of the first peak. The redox potentials $\left(E^{01} \& E^{02}\right)$ was determined at sweep rate $>0.2 \mathrm{~V} \mathrm{~s}^{-1}$ from the mean positions of the peak potentials of the cyclic voltammograms (Table 1). If the potential is switched at $0.68 \mathrm{~V}$, the cyclic voltammogram exhibited one anodic peak (I) coupled with small reductive peak (II) at sweep rate of $0.5 \mathrm{~V} \mathrm{~s}^{-1} \mathrm{Fig}$. 2C. This behaviour indicates that the presence of chemical step following the first charge transfer, i.e., $E C_{1}$ mechanism. Also, it was found that, the anodic peak potentials shift to more positive values with increasing the sweep rate reflecting the moderate rate of electron transfer that precedes the chemical step.

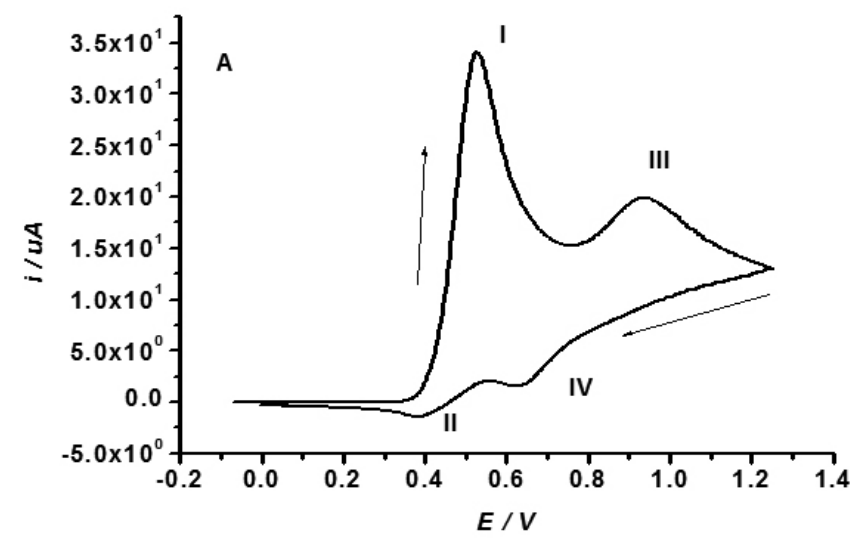

Fig. 2A. Cyclic voltammogram of iodide in $0.1 \mathrm{moL}^{-1} \mathrm{TBAP} / \mathrm{CH}_{2} \mathrm{Cl}_{2}$ at scan rate of $0.2 \mathrm{Vs}^{-1}$.

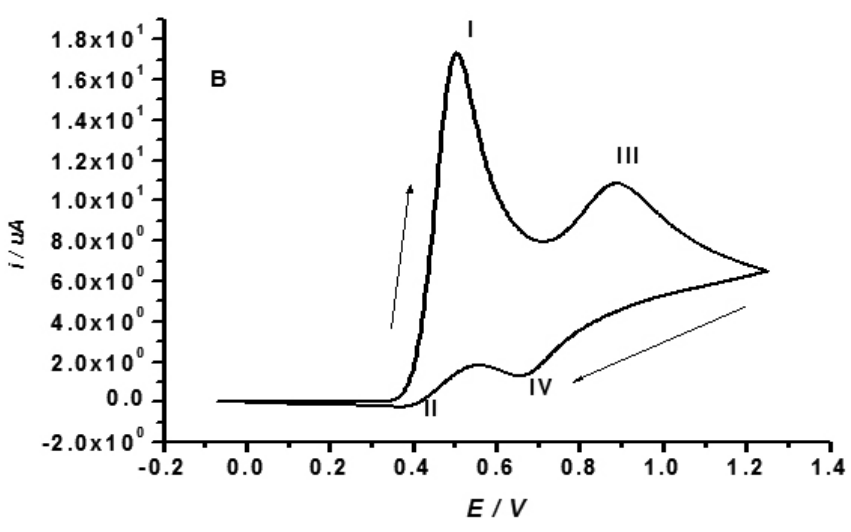

Fig. 2B. Cyclic voltammogram of iodide in $0.1 \mathrm{moL}^{-1} \mathrm{TBAP} / \mathrm{CH}_{2} \mathrm{Cl}_{2}$ at scan rate of $0.1 \mathrm{Vs}^{-1}$.

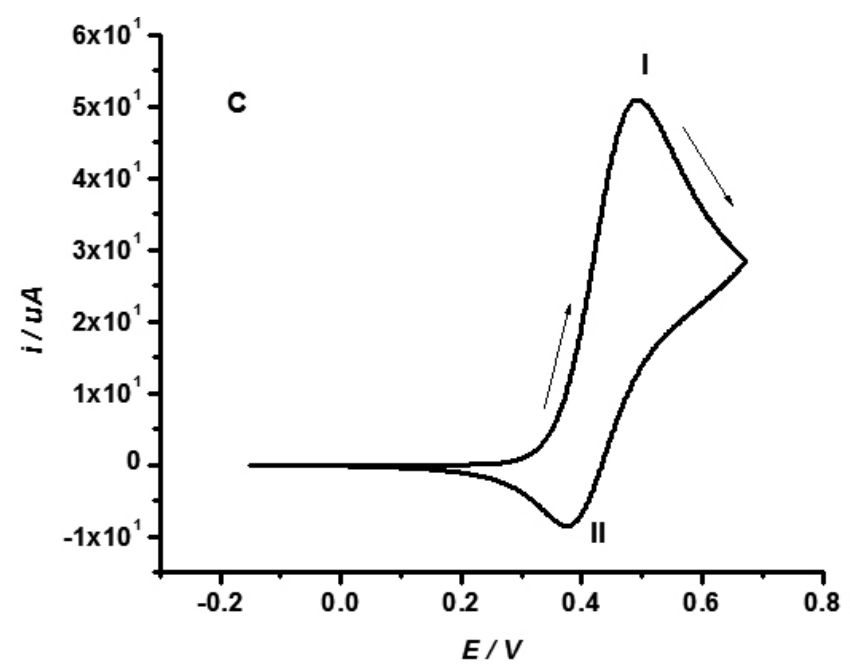

Fig. 2C. Cyclic voltammogram of the first peak of iodide in $0.1 \mathrm{~mol} \mathrm{~L}^{-1}$ $\mathrm{TBAP} / \mathrm{CH}_{2} \mathrm{Cl}_{2}$ at at sweep rate of $0.5 \mathrm{~V} \mathrm{~s}^{-1}$.

The standard heterogeneous rate constant $\left(k_{s}\right)$ of the investigated compound was calculated from the voltammograms via peak separation values, $\Delta E_{p}$ versus $\psi$ using the working curve established in literature. ${ }^{26}$ After background subtraction and correction for uncompensated resistance, the diffusion coefficient $D$ was determined from cyclic voltammetry using Eq. $1^{24}$

$$
i_{p}=\left(2.99 \times 10^{5}\right) n\left(\alpha n_{a}\right)^{1 / 2} S C^{b u l k} D^{1 / 2} v^{1 / 2}
$$

where $i_{p}$ is the peak current and the other terms have their usual definitions. The estimated D value was found to be $5.4 \pm 0.2 \times 10^{-5} \mathrm{~cm}^{2} \mathrm{~s}^{-1}$.

The influence of potential scan rate $(v)$ on the peak currents of iodide (peak I and peak III in TBAP/ $/ \mathrm{CH}_{2} \mathrm{Cl}_{2}$ was studied by cyclic voltammetry. Assume that $i \alpha v^{\mathrm{x}}$ when the electrode process is diffusion controlled, $x$ should take a value of 0.5 , and for adsorption controlled process it should take a value of 1.0. Fig. 3A indicated that peak $I$ and peak III increased linearly with increase of $v^{1 / 2}$, and the corresponding peak $\mathrm{I}-v$ and peak III $-v$ curves tilts (Fig. 3B). This confirmed that both of peak I and peak III at a GCE electrode are diffusion-controlled. ${ }^{26}$ 

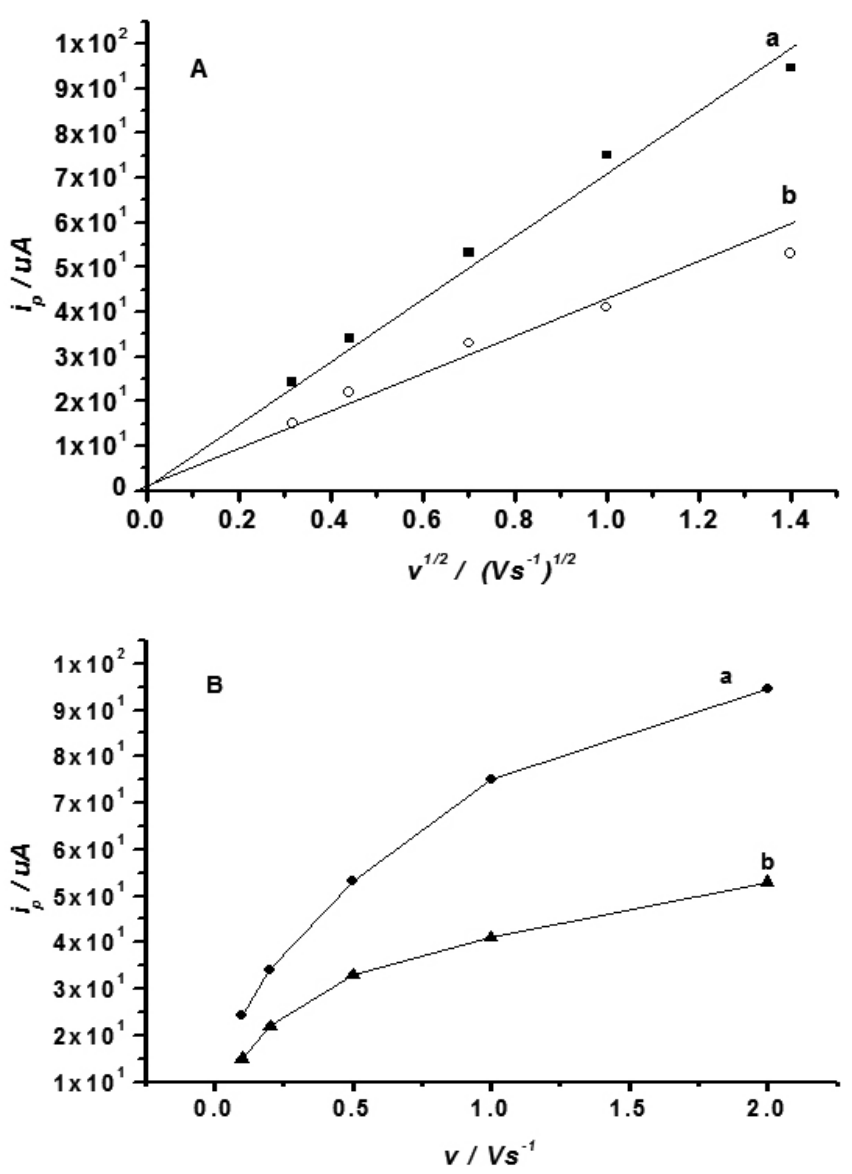

Fig.3 (A). Plot of $i_{p}$ vesus the square root of sweep rate of the first peak I (a) and of the second peak III (b) of iodide. \& (B) Plot of $i$ versus the sweep rate of the first anodic voltammetric peak I (a) and of the second anodic peak (III) of iodide (b).

Table 1: Electrochemical parameters of the electro-oxidation of iodide determined from different electrochemical techniques.

\begin{tabular}{|c|c|c|c|c|c|c|}
\hline & \multicolumn{6}{|c|}{ Electrochemical techniques } \\
\hline $\begin{array}{l}\text { Electrochemical } \\
\text { Parameters }\end{array}$ & $\mathrm{CV}$ & Conv & Decon & Sim & $\mathrm{CA}$ & $\mathrm{CP}$ \\
\hline$E^{\text {ol }}, \mathrm{V}$ & 0.433 & $\ldots$ & 0.435 & 0.432 & $\ldots$ & $-\cdots$ \\
\hline$E^{02}, \mathrm{~V}$ & 0.754 & $\cdots$ & 0.755 & 0.756 & $\ldots$ & $\cdots$ \\
\hline$k_{\mathrm{s} 1 \times 10^{5}, \mathrm{~m} \mathrm{~s}^{-1}}$ & 2.1 & $-\ldots$ & $\ldots-$ & 2.200 & 2.25 & $\ldots$ \\
\hline$k_{52} \times 10^{5}, \mathrm{~m} \mathrm{~s}^{-1}$ & 1.4 & $\ldots$ & $\ldots$ & 1.50 & $\ldots$ & $-{ }_{-}$ \\
\hline$D_{1} \times 10^{5}, \mathrm{~cm}^{2} \mathrm{~s}^{-1}$ & 5.4 & $\begin{array}{l}5.6^{\mathrm{s}} \\
5.3^{\mathrm{b}}\end{array}$ & 5.8 & 5.60 & 5.9 & 5.2 \\
\hline$D_{2} \times 10^{5}, \mathrm{~cm}^{2} \mathrm{~s}^{-1}$ & 3.1 & $\begin{array}{l}3.2^{\mathrm{a}} \\
3.5^{\mathrm{b}}\end{array}$ & 3.3 & 3.400 & - & 3.9 \\
\hline al & 0.38 & -- & -- & 0.390 & 0.38 & -- \\
\hline$a^{2}$ & 0.37 & - & -- & 0.380 & $\cdots$ & - \\
\hline $\mathrm{k}_{\mathrm{cl},} \mathrm{s}^{-1}$ & 2.50 & -- & - & 2.51 & --- & --- \\
\hline $\mathrm{k}_{02,} \mathrm{~s}^{-1}$ & 1.90 & -- & -- & 1.88 & --- & $-\ldots$ \\
\hline$\Delta \mathrm{H}^{*},\left(\mathrm{KJmo}^{-1}\right)$ & 602 & -- & -- & --- & -- & $\cdots$ \\
\hline$\Delta \mathrm{S}^{\sharp}\left(\mathbf{J k}^{-1} \mathbf{m o l}^{-1}\right)$ & -55.0 & - & --- & $-\cdots$ & $\cdots$ & --- \\
\hline$\Delta \mathrm{G}^{*}\left(\mathrm{KJJmo}^{-1}\right)$ & 15.5 & - & $-\ldots$ & --- & $-\ldots$ & - \\
\hline
\end{tabular}

(a) Value of $D$ determined via Eq. $3 \&$ (b) value of $D$ determined via Eq. 5.

CV: cyclic voltammetry, Conv: convolution transforms, Decon: deconvolution transforms, Sim: simulation, CA: chronoamperometry, CP: chronopotentiometry
Inspection of Table 1 revealed that, the redox potential of the second oxidation process is more positive than that of the first one, which revealed that the second process requires more energy than the first one. Also, the value of the first standard heterogeneous rate constant $\left(\mathrm{k}_{\mathrm{s} 1}\right)$ is larger than the second heterogeneous rate constant $\left(\mathrm{k}_{\mathrm{s} 2}\right)$ confirming that the first step of charge transfer is faster than the second charge transfer. The values of the transfer coefficient $\alpha_{1}$ and $\alpha_{2}$ behave in the same trend like $\mathrm{k}_{\mathrm{s} 1}$ and $\mathrm{k}_{\mathrm{s} 2}$, i.e the activation energy barrier of the first electron transfer is slightly less than that of the second electron transfer.

\section{Convolution -deconvolution voltammetry of iodide}

Convolutive voltammetry has been successfully applied to analysis of mechanism of several electrochemical processes. ${ }^{27-37}$ Convolution of the current with an inverse square root of time function was defined as: ${ }^{28,32}$

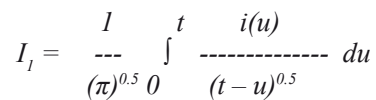

where $I_{l}$ is the convoluted current at the total elapsed time $(t), i(u)$ is the experimental current at time $u$. The diffusion coefficient of the investigated compound was determined, after applying background subtraction and correction for uncompensated resistance, from Eq. $3: 28$

$$
I_{\text {lim }}=n F S D^{1 / 2} C^{b}
$$

where $I_{\text {lim }}$ is the limiting value achieved for $I_{l}$ when the potential is driven to a sufficiently extreme value past the peak, and the other terms has their usual meanings.

Figure 4A gives an example of the $\mathrm{I}$ convolution of first oxidative peak I coupled with the reductive peak II illustrating the quasireversibility of the charge transfer process as shown from the separation between the forward and reverse sweep of the $I_{1}$ convolution. Also, the backward scan of convoluted current does not return to its initial value at the end of scan (Fig. 4A) confirming the presence of chemical step coupled with charge transfer The homogeneous chemical rate constant $(\mathrm{k})$ of the chemical process which follows the first charge transfer was calculated from the kinetic convolution $\left(\mathrm{I}_{2}\right)$ at sweep rate of $0.5 \mathrm{~V} \mathrm{~s}^{-1}$, which is defined as: ${ }^{38}$

$$
I_{2}=\frac{1}{\sqrt{ } \pi} \int_{0} \frac{\mathrm{t} i(\mathrm{u}) \exp \left[-\mathrm{k}_{\mathrm{c}}(\mathrm{t}-\mathrm{u})\right]}{\sqrt{\mathrm{t}-\mathrm{u}}}
$$

which are presented in Figure 4B as calculated from the appropriate value of the chemical rate constant obtained by inserting trial value of the homogeneous chemical rate constant $\left(\mathrm{k}_{\mathrm{c}}\right)$ into the convolution calculation until $I_{2}$ returned to zero immediately after the wave. The true $\mathrm{k}_{\mathrm{c}}$ value determined from $\mathrm{I}_{2}$ convolution is $2.5 \mathrm{~s}^{-1}$, which agree well with the values calculated from digital simulation.

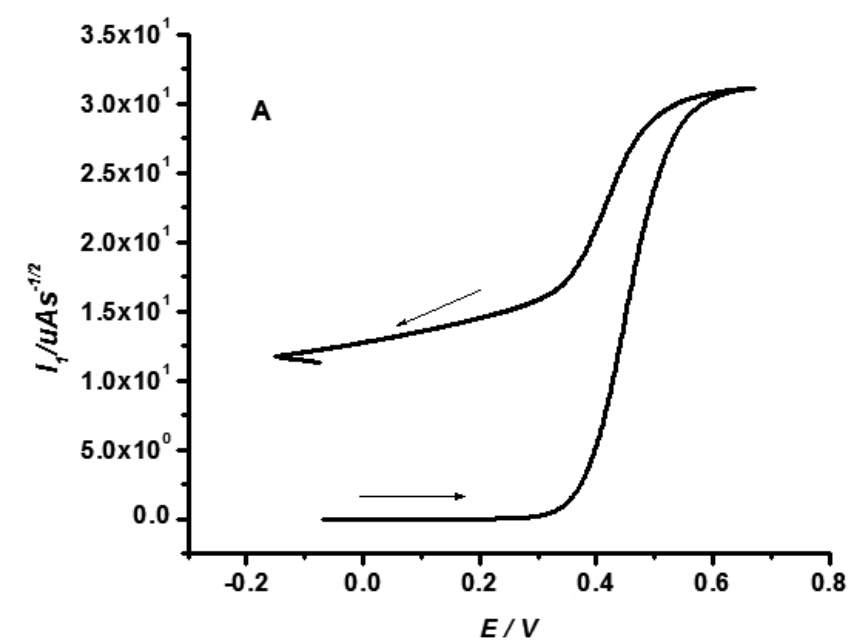




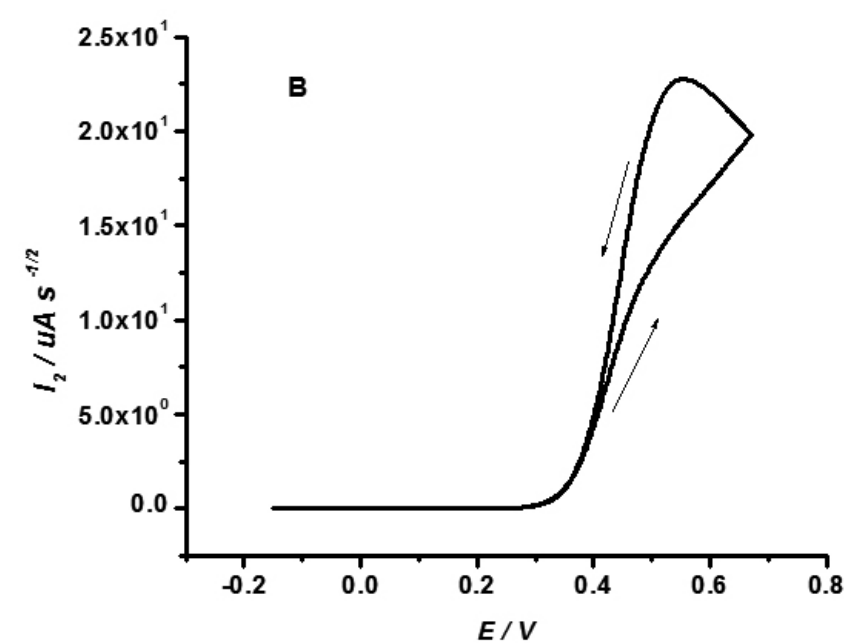

Fig. 4. $I_{1}$ convolution voltammogram (A) \& $I_{2}$ kinetic convolution voltammogram of the first peak of iodide in $0.1 \mathrm{~mol} \mathrm{~L}^{-1} \mathrm{TBAP} / \mathrm{CH}_{2} \mathrm{Cl}_{2}$ at sweep rate of $0.5 \mathrm{~V} . \mathrm{s}^{-1}$

The diffusion coefficient was also determined from a simple and accurate method via combination between the definition of both limiting convoluted current and peak current of the cyclic voltammogram using Eq. 5:33

$$
I_{\text {lim }}=i_{p} / 3.099\left(\alpha n_{a} v\right)^{I / 2}
$$

where $i$ was defined in Eq. 1, and the other parameters have their usual meanings. The $I_{1}$ convolution of the investigated iodide illustrated in Figure 5 shows a distinct separation between the forward and reverse sweep and clearly indicates the sluggishness of electron transfer of the oxidation process. At all sweep rates, the reverse sweep of the $I_{l}$ convolution does not return to zero due to chemical reaction appears at time scale of the experiment. Values of the diffusion coefficient $D$ evaluated via Eqs $3 \& 5$ are listed in Table 1 .

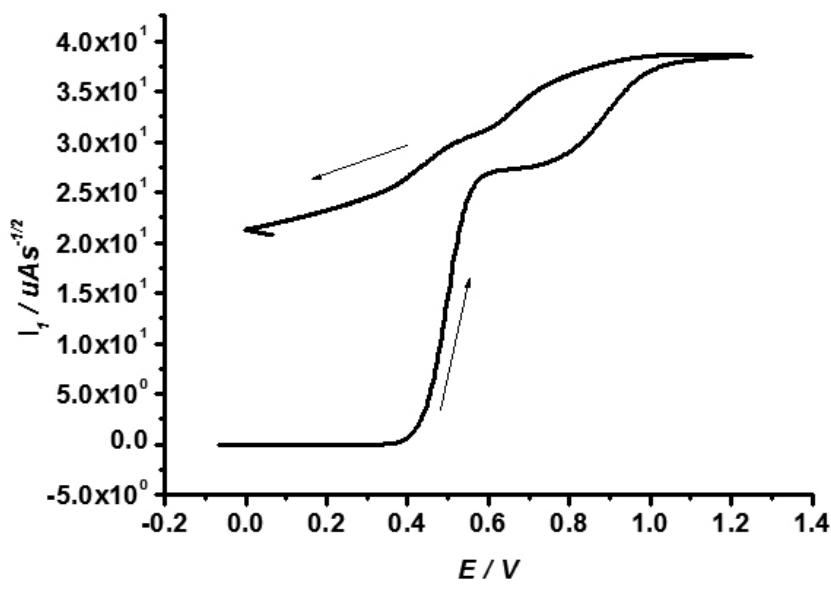

Fig. 5. Convolutive voltammetry $\left(\mathrm{I}_{1}\right)$ of the oxidative cyclic voltammogram of iodide at a sweep rate of $0.2 \mathrm{~V} \mathrm{~s}^{-1}$.

The deconvolution transforms gives a rapid assessment of either the electron transfer regime or value of $E_{12}$. Also, as shown in Figure 6, the different peak heights of the forward and backward sweeps of deconvoluted current $\left(e_{p h} / e_{f}\right)$ give a strong evidence for a chemical reaction following the electron transfer (Table 2). The mean values of the cathodic $\left(E_{p c(d e c o n)}\right)$ and the anodic $(E)$ peak potentials were taken as the redox potentials $\left(E^{0}\right)$ of the system under consideration. The estimated value of $E^{0}$ is given in Table 1.

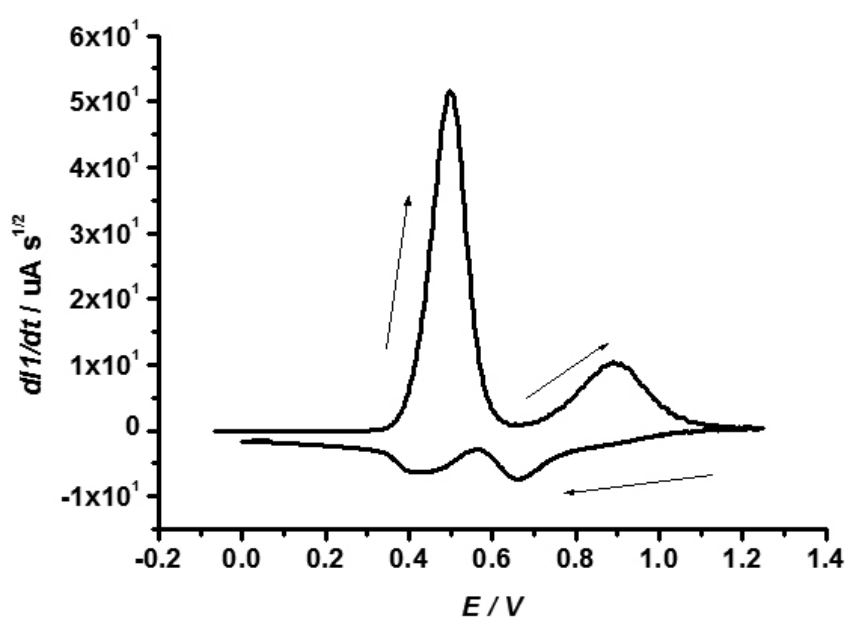

Fig. 6. Deconvolution voltammetry $\left(\mathrm{dI}_{1} / \mathrm{dt}\right)$ of iodide at a sweep rate of $0.2 \mathrm{~V} / \mathrm{s}^{-1}$

The cathodic half-peak width $\left(w^{p}\right)$ was taken as a route for knowing the nature of electron transfer. ${ }^{34}$ The calculated values were in the range of 55 - $85 \mathrm{mV}$ at $v=0.2-1.0 \mathrm{~V} \mathrm{~s}^{-1}$ (Table 2). The values of $w^{p}$ shown in Table 2 confirmed the quasi-reversibility of the system under consideration.

Table 2: Peak characteristics of the first oxidative peak of iodide extracted from cyclic, deconvolution transforms voltammetry and digital simulation techniques at $1.0 \mathrm{~V} \mathrm{~s}^{-1}$.

\begin{tabular}{|lrc|}
\hline $\mathrm{E}_{\mathrm{p}}-\mathrm{E}_{\mathrm{p} / 2}, \mathrm{mV}$ & $57^{(\mathrm{a})}$ & $56^{(\mathrm{c})}$ \\
$w^{p}, \mathrm{mV}$ & $85^{(\mathrm{b})}$ & $86^{(\mathrm{c})}$ \\
$\Delta \mathrm{E}_{\mathrm{p} \text { deconv }} \mathrm{mV}$ & $274^{(\mathrm{b})}$ & $275^{(\mathrm{c})}$ \\
$e_{p b} / e_{p f}$ (deconv) & $0.28^{(\mathrm{b})}$ & $0.29^{(\mathrm{c})}$ \\
\hline
\end{tabular}

(a) Values determined from CV, (b) Values determined from deconvolution and (c) values determined from digital simulation.

The diffusion coefficient was also determined from deconvolution transforms using Eq. $(6)^{34}$

$$
e_{p=} \quad \frac{\alpha n^{2} F^{2} v C D^{1 / 2}}{3.367 R T}
$$

where $e$ is the peak height (in Ampere) of the forward deconvolution sweep and the remaining terms have their usual meanings. Value of the diffusion coefficient estimated from this method is given in Table 1.

The proportionalities of $e$ with sweep rate $v$ are presented and shown in Fig. 7. It is clear that for both anodic peaks I and III the linearity is satisfactory and the lines pass through the origin confirming the diffusion controlled nature of iodide oxidation at glassy carbon electrode in $0.1 \mathrm{~mol} \mathrm{~L}{ }^{-1} \mathrm{TBAP} / \mathrm{CH}_{2} \mathrm{Cl}_{2}$. 


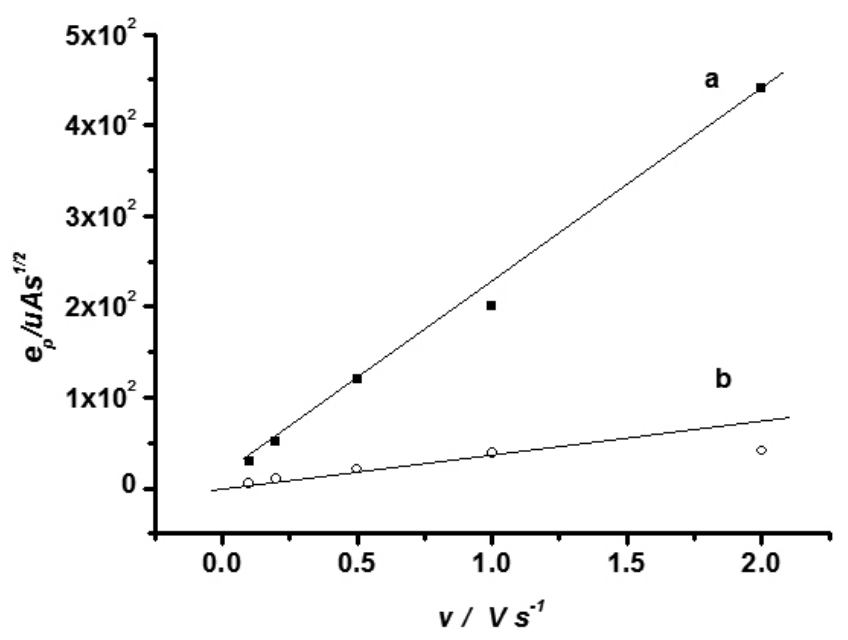

Fig. 7. Plot of e vesus the sweep rate of the first peak (line a) and of the second peak (line $b)^{p}$

Also from combination between convolution and deconvolution transforms the following relation was deduced:

$$
\begin{gathered}
n=\frac{e_{p} 3.367 R T}{\alpha F v I_{\text {lim }}} \\
=\frac{0.086 e_{p}}{I_{\text {lim }} \alpha F v}
\end{gathered}
$$

Where $\mathrm{n}$ is the number of electrons consumed in electrode reaction, the other symbols have their usual definitions. From Eq. 7 the number of electrons was calculated and found to be $1.8 \approx 2$ for the first peak and $0.93 \approx 1$ for the second one. As shown the number of electrons was determined without knowing the electrode surface area which considers a good, precise and simple method for determination of the number of electrons involved in the electrode reaction via convolution - deconvolution voltammetry.

As a result, peak 1 is a two-electron oxidation wave yielded from iodide to triiodide. The oxidation mechanism of peak I may be tentatively assigned to:

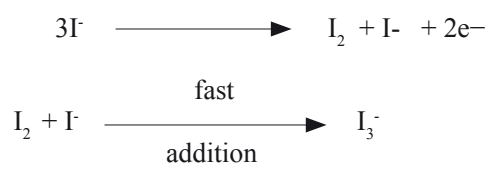

The second anodic peak (III) yielded from triiodide is one electron oxidation wave. The oxidation mechanistic pathway may be due to the following scheme:

$$
3 \mathrm{I}_{2}+3 \mathrm{CH}_{2} \mathrm{Cl}_{2} \stackrel{3 \mathrm{I}_{2}+2 \mathrm{e}}{\text { interaction }} \text { with solvent } \longrightarrow 3\left[\mathrm{CH}_{2} \mathrm{Cl}_{2} \mathrm{I}^{+}[\mathrm{I}]^{-}\right.
$$

\section{Digital simulation}

A direct test of the determined electrochemical parameters was performed by generating the simulated cyclic voltammogram of iodide using the average values of the electrochemical parameters extracted experimentally and comparing it with the voltammogram recorded experimentally. Figure 8 shows a good agreement between the simulated and experimental

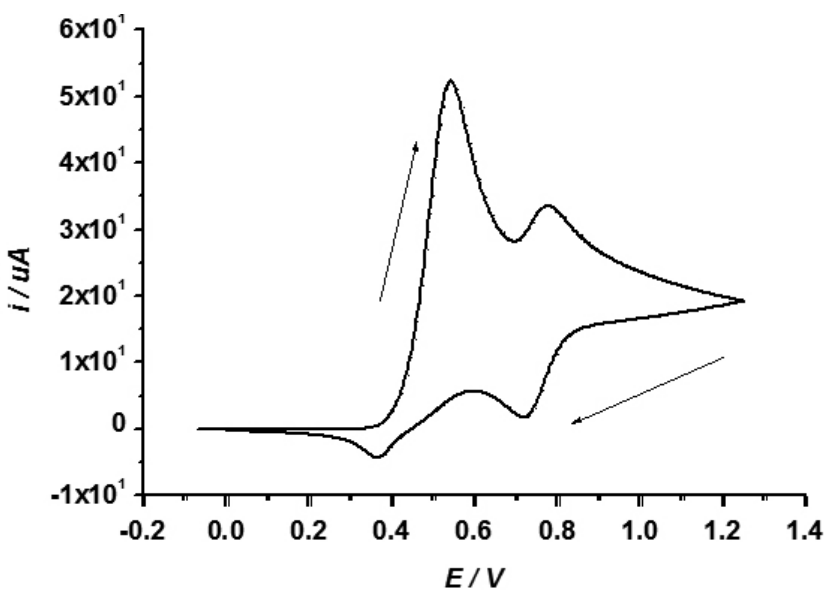

Fig. 8. Matching between experimental voltammogram ( — $)$ and simulated voltammogram (...........) at a sweep rate of $0.5 \mathrm{~V} / \mathrm{s}$.

voltammograms at a scan rate of $0.5 \mathrm{~V} \mathrm{~s}^{-1}$ verifying a moderately fast chemical steps preceded by a transfer of one- two electron then one quasireversible electron transfer, i.e. $E C_{1} E C_{2}$ scheme.

Effect of temperature on the rate of charge transfer

The rate of heterogeneous electron transfer $(k)$ of iodide was investigated as a function of temperature $(T)$. It was found that lowering the temperature of the system decrease the rate of electron exchange between electrode and the electroactive species in the electrochemical cell. Figure 9 shows an example response of the plot of $\ln (k / T) v s .1 / T$ of the first charge transfer peak. The enthalpy of activation $\Delta H^{\neq}$and entropy of activation $\Delta S^{\ddagger}$ were calculated from the slope and the intercept of the plot using Eq. (8).

$$
\operatorname{Ln}\left(k_{s} / T\right)=\ln (k / h) \frac{\Delta H^{\ddagger}}{R T}+\frac{\Delta S^{\ddagger}}{R}
$$

where $k$ is the Boltzmann constant, $h$ is the Plank constant and the other parameters have their usual definitions. Values of $\Delta G^{\ddagger}$ determined from the values of $\Delta H^{\ddagger}$ and $\Delta S^{\ddagger}$ are given in Table 1 .

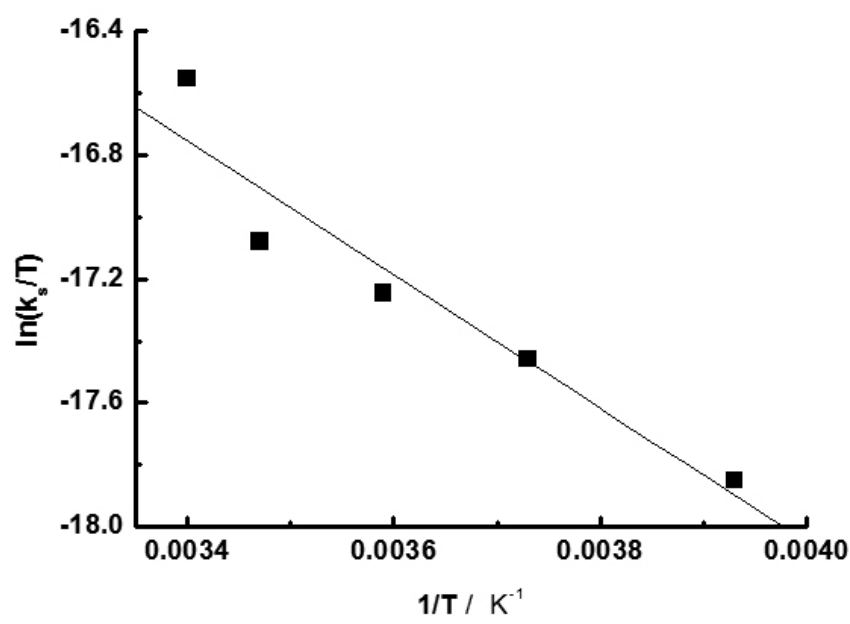

Fig.9. plot of $\ln \mathrm{k} / \mathrm{T}$ versus $1 / \mathrm{T}$ of the first oxidative peak of iodide

The calculated values of enthalpy of activation $\Delta H^{\ddagger}$, entropy of activation $\Delta S^{\ddagger}$ and free energy of activation $\Delta G^{\ddagger}$ indicated that increase of the activation energy barrier upon lowering the temperature of the system which may be attributed to the slow reactant transport at temperature between $-20^{\circ} \mathrm{C}$ and $21{ }^{\circ} \mathrm{C}$ of the electrolyte indicates a larger hindrance to the motion of the electroactive iodide species. 


\section{Effect of temperature on the diffusion coefficient}

The diffusion coefficient of the iodide was determined at low temperature in $0.1 \mathrm{~mol} \mathrm{~L}^{-1} \mathrm{TBAP} / \mathrm{CH}_{2} \mathrm{Cl}_{2}$ according to equation $9: 39$

$$
i_{p}=0.4463\left(F^{3} / R\right)^{1 / 2} \alpha^{1 / 2} n^{3 / 2} A C v^{I / 2}(D / T)^{1 / 2}
$$

which associates the peak current $\left(i_{p}\right)$ to the diffusion coefficient $D$ when the charge transfer is slow and assuming transfer coefficient $\alpha$ to be $0.5^{39}, \mathrm{~A}$ is the electrode surface area and the other symbols have their usual meanings. Values of the diffusion coefficient determined at various temperatures via Eq.(9) are listed in Table 3, which indicate decreasing the diffusion coefficient $(D)$ by lowering the temperature of the system.

Table.3 Experimental diffusion coefficients for iodide extracted from the first peak of the cyclic voltammograms at various values of temperature.

\begin{tabular}{|cc|}
\hline $\mathrm{T} / \mathrm{K}$ & $\mathrm{D}_{1} \times 10^{5} / \mathrm{cm}^{2} \mathrm{~s}^{-1}$ \\
\hline 288 & 4.80 \\
278 & 3.90 \\
268 & 2.60 \\
253 & 1.51 \\
\hline
\end{tabular}

The diffusion coefficients values for higher temperatures were obtained by extrapolation of $\log \mathrm{D}$ vs. 1/T plot (Fig. 10). Value of the diffusion coefficient determined from extrapolation method agrees well with that determined from cyclic voltammetry, convolution, deconvolution voltammetry and digital simulation methods.

It was found that, an decrease in temperature lead to increases of the height of the potential energy barrier, ${ }^{40}$ thus hinder the electron transfer process at the electrode surface. Moreover, an decrease in temperature decreases the kinetic energy of I,- which may be accompanied by an decrease in the rate of diffusion and eventually resulting in an decrease in $\mathrm{k}_{\mathrm{s}}$ value.

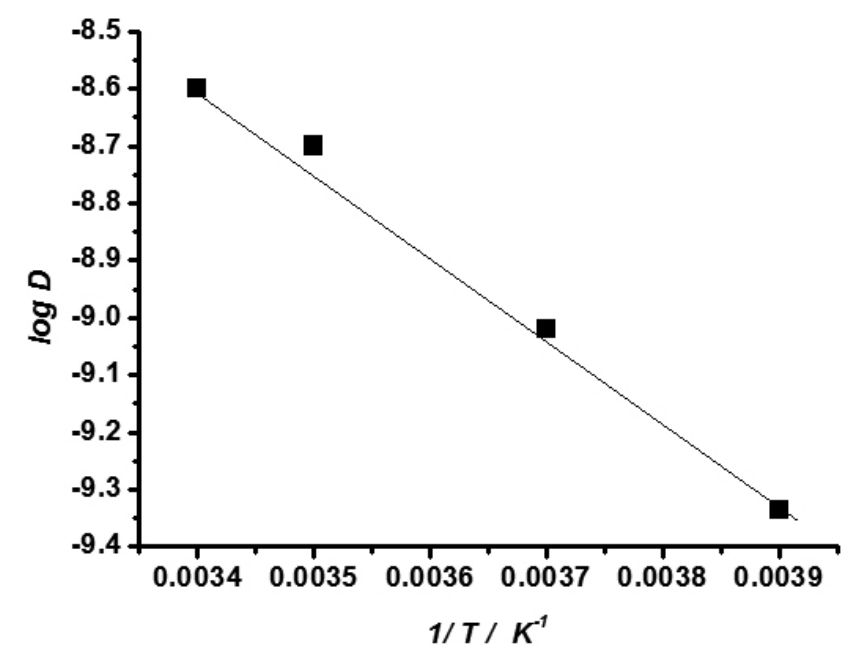

Fig.10. plot of $\log \mathrm{D}$ versus $1 / \mathrm{T}$ of the first oxidative peak of iodide.

Chronoamperometry and chronopotentiometry

Chronoamperogram of $2 \times 10^{-4} \mathrm{~mol} \mathrm{~L}^{-1}$ solution of the iodide in $0.1 \mathrm{~mol}$ $\mathrm{L}^{-1} \mathrm{TBAP} / \mathrm{CH}_{2} \mathrm{Cl}_{2}$ at a glassy carbon electrode recorded at a potential step equals to $E_{1 / 2}$ is shown in Figure 11. The rate constant $k_{f}$ was calculated from Eq.(10): $:^{34}$

$$
i(t)=-\beta I_{1}+u
$$

where $u=n F A C^{b} k(D)^{1 / 2}$ and $\beta=k(D)^{1 / 2}$. Measurements of both the intercept at $\mathrm{I}_{1}=0$ and the slope of the linear plot of $i(t)$ versus $I_{l}$ give $k_{f}$.

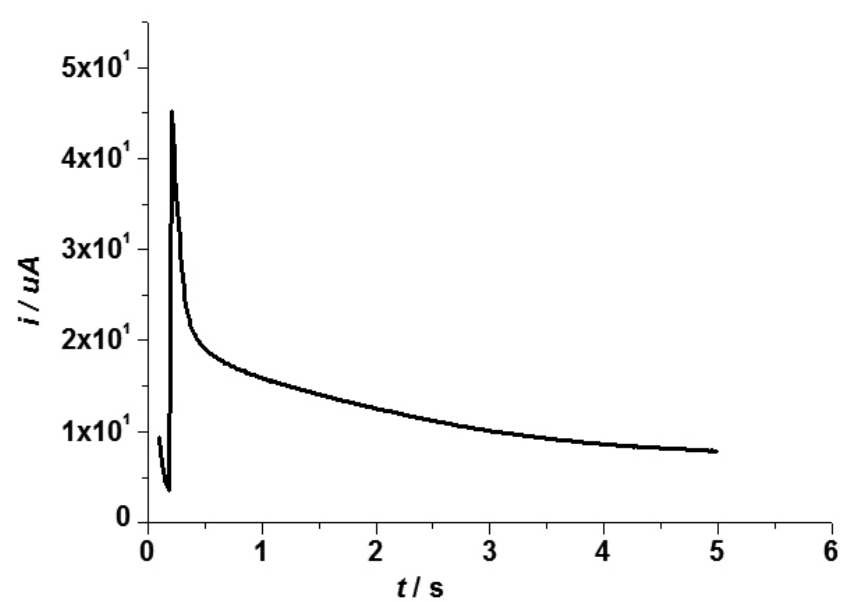

Fig. 11 Chronoamperogram of the first anodic oxidative peak of iodide

Here, the fundamental relationship between the rate of the electron transfer and the potential of the electrode is discussed in terms of the Butler-Volmer treatment which can be expressed in the form of Eq. 11. ${ }^{34}$

$$
\ln k_{f}=\frac{\alpha n F}{R T}\left(E_{f}-E_{1 / 2}\right)+\ln k_{s}
$$

Value of $\alpha$ was estimated from slope of the linear plot of $\ln k_{f} v s$. $\left(E_{f}-E\right.$ ${ }_{1 / 2}$ ) and was found to be 0.38 , while value of the standard heterogeneous rate constant $k$ was estimated at the point at which $E_{f}=E_{122}$ and was found to be $2.25 \times 10^{-5} \mathrm{~m} \mathrm{~s}^{-1}$. Both values are compared well with those obtained from cyclic voltammetry and digital simulation data (Table 1 ).

The presentation of $i v s t$ of the voltammogram at sweep rate of $1.0 \mathrm{~V} \mathrm{~s}^{-1}$ is shown in Fig 12. The plot produce discontinuity $\Delta i c_{c}$ at $\mathrm{t}=7.05 \mathrm{~s}$ due to the reversibility of the scan. By selecting the data points a cottrel plot is obtained as current versus the reciprocal square root of time. The slope of cottrel plot yields a diffusion coefficient $\mathrm{D}=5.9 \times 10^{-5} \mathrm{~cm}^{2} \mathrm{~s}^{-1}$ and $3.7 \times 10^{-5} \mathrm{~cm}^{2} \mathrm{~s}^{-1}$ of the first and second peak respectively.

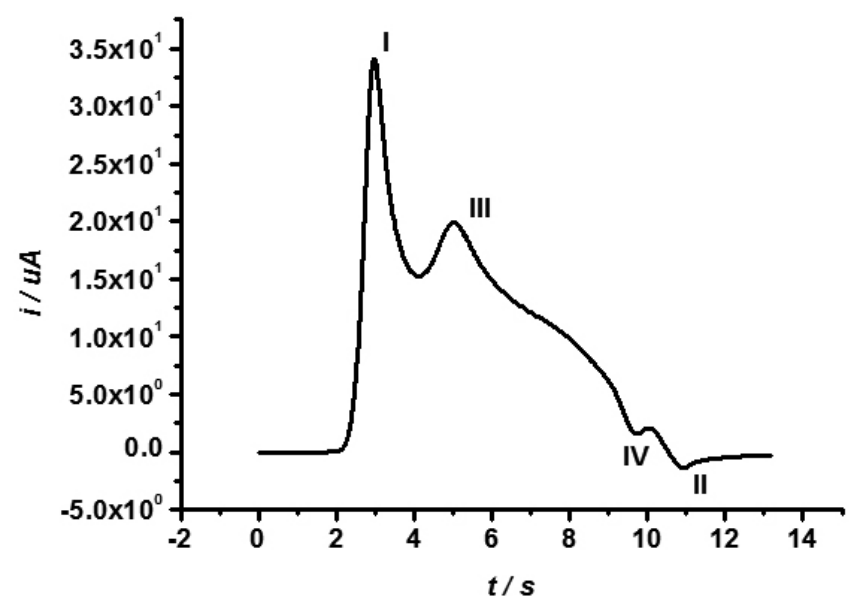

Fig. 12. Representation of $i$ vs $t$ of cyclic voltammogram of iodide.

Inspection of Fig. 12 revealed that, the height of the forward and backward peaks is different, i.e the height of peak I is unequal to the height of peak II and the height of peak III is unequal to the height of peak IV confirming the complication of both charge transfer of iodide with chemical process.

Chronopotentiogram of $2 \times 10^{-4} \mathrm{~mol} \mathrm{~L}^{-1}$ solution of the iodide recorded in $0.1 \mathrm{~mol} \mathrm{~L}^{-1} \mathrm{TBAP} / \mathrm{CH}_{2} \mathrm{Cl}_{2}$ at a glassy carbon electrode displayed two oxidation transition time in agreement with the two anodic oxidation voltammetric peaks. The chronopotentiometric transition time was analyzed via Eq.12 ${ }^{34}$ 


$$
I_{l i m}=2 i_{c}\left\{\mathrm{t}_{\mathrm{s}} / \pi\right\}^{1 / 2}=\left(n F A C^{b} D^{1 / 2}\right)
$$

where $i_{c}$ is the polarization current, $t_{s}$ is the transition time of the investigated iodide, and the other symbols have their usual definitions. Values of diffusion coefficient determined from chronopotentiometry were listed in Table 1. In this work, It was seen that, various methods are used to measure the diffusion coefficients of the electroactive species, including cyclic voltammetry, convolutive voltammetry, deconvolutive voltammetry, digital simulation, chronoamperometry and chronopotentiometry at a glassy carbon electrode. The values of the diffusion coefficient displayed in Table 1 showed a very good agreement for the six different methods confirming and supporting the accuracy of the methods used for calculation the diffusion coefficient of the investigated system.

\section{REFERENCES}

1. N. N. Greenwood, A. Earnshw, Chemistry of elements (2 ${ }^{\text {nd }}$ ed.), Oxford: Butterworth- Heinemann. (1997).

2. F. C. Kupper, M. C. Feiters, W. Meyer-Klaucke, P. M. H. Kroneck, A. Butler, Iodine Accumulation in Laminaria (Phaeophycea).: an Inorganic Antioxidant in a Living System, Proceedings of the $13^{\text {th }}$ Congress of the Federation of European Societies

of Plant Physiology, Heraklion, Greece, Septmber 2-6, p. 571, (2002).

3. E. Ar Gall, F.C. Kupper, B. Kloareg, Laminaria digitata Botanica Marna. 47, 30, (2004).

4. F. C. Kupper et al, Proc Natl Acad Sci USA., May 5. 99, 5890, (2008).

5. S. Venturi, F. M. Donati, A. Venturi, M., Thyroid. 10, 727, (2000).

6. S. Venturi, M. Venturi, Iodine and Evolution, DIMI-MARCHE NEWS, Dipartimento Interaziendale di Medicina Interna della Regione Marche (Italy). (2004).

7. S. Venturi, M. Venturi, European EPI-Marker, 11,1, (2007).

8. N. N. Greenwood, A. Earnshaw, Chemistry of the Elements, Pergamon, Oxford. (1984).

9. E.J. Underwood, Trace Elements in Human and Animal Nutrition, fourth ed., Academic Press, New York. p. 271, (1997).

10. S. Venturi, M. Venturi, Eur. J. Endocrinol. 140, 371, (1999).

11. M. Sazarashi, Y. Ikeda, J. Nucl. Sci. Technol. 31, 620, (1994).

12. H. Ohno (Ed.), Electrochemical Aspects of Ionic Liquids, Wiley. (2005).

13. P. Bonhote, A.P. Diaz, M. Armand, N. Papagergiou, K. Kalyanasundram, M. Gra $\square$ tzel, Inorg. Chem. 35, 168, (1996).

14. N. Papageorgiou, Y. Anatassov, M. Armand, P. Bohnote, H Pettersen, A. Azam, M. Gra $\square$ tzel, J. Electrochem. Soc. 143, 3099 , (1996).

15. B. O’Regan, M. Gra $\square$ tzel, Nature. 353, 737, (1991).
16. R. Kawano, H. Matsui, C. Matsuyama, A. Sato, Md. A.B. Hasan Susan, N. Tanabe, M.Watanabe, J. Photochem. Photobiol. A: Chem. 164, 87, (2004).

17. H. Wang, X. Liu, Z. Wang, H. Li, D. Li, Q. Meng, L. Chen, J. Phys. Chem. B. 110, 5970, (2006).

18. L.. Niu, Hu. Zhang, F. Wei , W. Suxiang, C. Xiaoli , L. Pengpeng, Applied Surface science. 252, 1634, (2005).

19. L. Papouchado, R. N. Adams, S.W. Feldberg, Electroanal. Chem. 21 , 408, (1969).

20. S.W. Feldberg, Digital Simulation in Electrochemistry, in: A.J. Bard (Ed), Electroanalytical Chemistry, Marcel Dekker, New York, (1969).

21. D. Britz, Digital Simulation in Electrochemistry, Springer, Berlin. (1981).

22. L.M. Dane', L.J.J. Janssen, J.G. Hoogland, Electrochim. Acta. 13, 507, (1968).

23. U. Gutman, Fortscher. Chem. Forsch. 44, 142, (1972).

24. I. M. Kolthoff, J. Jordan, J. Am. Chem. Soc. 75, 1571, (1953)

25. I. M. Kolthoff, J.F. Coetzee, J. Am. Chem. Soc. 79, 1852, (1957).

26. R.S. Nichlson, Anal. Chem. 37, 1351, (1965).

27. W. Wang, D. Lee, A.M. Leone, R.W. Murray, Chem. Phys. 319, 126 (2005).

28. I. S. El-Hallag, M. M. Ghoneim, Monats. Chem. 127, 487, (1996).

29. R. S. Nicholson, I. Shain, Anal. Chem. 36, 706, (1964).

30. J. G. Gaudiello, T. C. Wright, R. A. Jones, A. J. Bard, J. Am. Chem. Soc. 107, 888, (1985)

31. J. C. Imbeaux, J. M. Saveant, J. Electroanal. Chem. 44, 169, (1973).

32. I. D. Dobson, N. Taylor, L.R.H. Tipping, in Electrochemistry, Sensor and Analysis, Elsevier. Amsterdam. P 61. (1986).

33. I. S. El-Hallag, M. M. Ghoneim and E. Hammam, Anal.Chem. Acta. 414 $173,(2000)$.

34. M. M. Ghoneim, I. S. El-Hallag, Monatsh . Chem. 130, 525, (1999).

35. K. B. Oldham, Anal Chem. 58, 2296, (1986).

36. I. S. El-Hallag, A. M. Hassanein and M. M. Ghoneim. Monatsh. Chem. 126, 1075, (1995).

37. S. A. El-Daly, I. S. El-Hallag, E. M. Ebied, M. M. Ghoneim, Chin. J. Chem. 27, 241, (2009).

38. I. S. El-Hallag, A. M. Hassanien., Collect. Czech. Chem. Commun. 64, 1953, (1999).

39. J.N. Richardson, J.Harvey, R.W. Murray, J Phys. Chem. 98, 13396, (1994).

40. L.N. Trevani, E. Calvo, H.R. Corti., Electrochem. Commun. 2, 312 , (2000). 